\title{
Testing the Out-of-Sample Forecasting Ability of a Financial Conditions Index for South Africa
}

\author{
Kirsten Thompsona, ${ }^{\mathrm{a},}$, Reneé van Eyden ${ }^{\mathrm{a}}$, Rangan Gupta ${ }^{\mathrm{a}}$ \\ a Department of Economics, University of Pretoria, Pretoria 0002, South Africa \\ Corresponding author. Email address: kirsten.thompson@lantic.net
}

\begin{abstract}
The importance of financial instability for the world economy has been severely demonstrated since the 2007/08 global financial crisis, highlighting the need for a better understanding of financial conditions. We consider a financial conditions index (FCI) for South Africa which is constructed from 16 financial variables and test whether the FCI does better than its individual financial components in forecasting the key macroeconomic variables of output growth, inflation and interest rates. Two sets of out-of-sample forecasts are obtained - one from a benchmark AR model and one from a nested ARDL model which includes one financial variable at a time. This concept of forecast encompassing is used to examine the out-of-sample forecasting ability of these financial variables as well as of the FCI, while also controlling for data-mining. We find that the FCI has good out-of-sample forecasting ability with respect to manufacturing output growth at the one, three and six month horizons, but has no forecasting ability with respect to inflation and interest rates ${ }^{1}$.
\end{abstract}

Keywords: financial conditions index; forecast encompassing; data-mining

JEL Classification: C22, C53, G01

${ }^{1}$ The authors are grateful for comments received by Christiane Baumeister and two anonymous referees. 


\section{Introduction}

The impact of financial instability on the world macroeconomy has been severely demonstrated since 2007-08's global financial crisis, highlighting the need for a better understanding of financial conditions. Thompson, Van Eyden and Gupta (forthcoming) construct a financial conditions index (FCI) for South Africa to capture in a single indicator the full spectrum of financial variables that affect the South African economy. The aim of this paper is to investigate whether Thompson, et al.'s (forthcoming) FCI can act as an 'early warning indicator' for impending macroeconomic instability caused by deteriorating financial conditions by means of out-of-sample forecasting tests ${ }^{2}$. To this end we test whether the estimated FCI does better than its individual financial components in forecasting key macroeconomic variables, namely output growth, inflation and an interest rate.

The concept of forecast encompassing is used to examine the forecasting ability of these variables following Rapach and Weber (2004). They consider the forecasting power of ten financial variables with respect to real GDP growth and industrial production growth in the U.S. over the period 1985M01 to 1999M04, to test and complement a similar study by Stock and Watson (2003). This also builds on work that relies on relative MSFE criteria for assessing forecasting ability, such as Thoma and Gray (1998) and Kışınbay (2007). Forecast encompassing is preferred to equal accuracy tests because forecast combination has often been found to improve forecast accuracy (Clements and Harvey, 2007).

The forecast encompassing approach used in this paper is based on two sets of out-of-sample forecasts for output growth, inflation, and the Treasury Bill rate. The two forecasts are obtained from an autoregressive distributed lag (ARDL) model including one financial variable at the time, and a benchmark autoregressive (AR) model. An optimal composite forecast is formed as the convex combination of these two forecasts and is interpreted as follows: if the optimal weight attached to the ARDL model's forecast is zero, then the ARDL model does not contain information that is useful for forecasting the chosen macroeconomic variable apart from the information already contained in the AR benchmark model. In other words, the AR model's forecasts encompass those of the ARDL model. Instead, if the optimal weight attached to the ARDL model's forecast is larger than zero, then the ARDL model does contain information that is useful for forecasting the chosen macroeconomic variables in addition to the information already contained in the AR benchmark model. The generic null hypothesis for these tests can then be stated as: the AR benchmark out-of-sample forecast encompasses the ARDL out-of-sample forecast (where the ARDL model includes the selected financial variable or the FCI); i.e. the AR model is the "better" forecasting model, which implies that the selected financial variable or FCI is not relevant in forecasting the chosen macroeconomic variable.

So for each financial variable and the FCI, we construct recursive out-of-sample forecasts of manufacturing output growth, inflation and the Treasury Bill yield over the out-of-sample period of 1986M01-2012M01, using an ARDL model that includes the chosen financial variable or FCI as an explanatory variable. As suggested by Rapach and Weber (2004) we test the above null hypothesis of

\footnotetext{
${ }^{2}$ Thompson, et al. (forthcoming) found that the estimated FCI has strong in-sample causality characteristics with respect to manufacturing output growth and the Treasury Bill yield.
} 
an encompassing AR model forecast using various statistics proposed by Harvey, Leybourne and Newbold (1998) and Clark and McCracken (2001).

The remainder of the paper is organised as follows: Section 2 presents a discussion of the data used to compile the FCI and used in the forecast encompassing exercises; while details on the construction of the FCI to be tested are discussed in Section 3. Section 4 presents Rapach and Weber's (2004) econometric methodology used in the forecast encompassing tests, including derivations of the five test statistics used for inference. The empirical out-of-sample forecast results are presented in Section 5, along with adjustments made to the test statistics so as to account for data-mining, as well as discussions of the individual predictors' economic significance (for those predictors surviving datamining). Section 5 also provides the forecasting performance of the estimated FCI. Section 6 concludes the paper.

\section{Data}

In compiling their FCI, Thompson, et al. (forthcoming) choose series that encompass measures in levels, as well as volatility measures. The data series included in the compilation of the FCI are (see Table 6 in the Appendix): South African financial asset prices; South African property prices; global asset prices; the real Rand-US Dollar exchange rate to capture global effects; the yield on the Johannesburg Stock Exchange (JSE); a global indicator of confidence; four South African interest rate spread measures, namely the bond spread, mortgage spread, treasury bill spread and term spread; US monetary policy measured by the Federal Funds rate; South African M3 money supply growth; credit extended to the South African private sector; and South African asset price volatility. The data set covers the sample of 1966M02 - 2012M01. The US Census X-12 procedure is used to seasonally adjust the data for series not already seasonally adjusted. Unit roots are tested for using the Ng-Perron (2001) procedure ${ }^{3}$, and non-stationary series are differenced to be made stationary. Finally, all data is standardised ${ }^{4}$ before compiling the FCI.

The data series used in the forecasting exercises in this paper include: the estimated FCI; each of its sixteen individual component series; a measure of output growth - the month-on-month rate of change in South Africa's Manufacturing Production Index; a measure of inflation - the month-onmonth rate of change in the consumer price index (CPI); and the 3-month Treasury Bill yield. The latter three series are the macroeconomic variables with respect to which we test the FCI's forecasting ability. Figure 2 in the Appendix shows the three macroeconomic series compared graphically to the estimated FCI.

\section{FCI Construction}

We choose to use an FCI in our model, given its useful ability of summarising the impact of monetary policy on financial prices, and hence future output and inflation (Mayes and Viren, 2001). An FCI is furthermore an attractive measure to use, as it generally comprises high frequency data, therefore

\footnotetext{
${ }^{3}$ Unit root test results are available from the authors upon request.

${ }^{4}$ Standardising the data enables analysis and comparison of the sizes of the impacts of the FCIs.
} 
having the potential to provide estimates and forecasts at shorter intervals - something that is especially desirable in the South African context of quarterly or annual macroeconomic forecasts.

The FCI estimated in Thompson, et al. (forthcoming) is compiled using principal components analysis (PCA) applied to a set of sixteen monthly financial variables (see Table 6). PCA is useful for combining many variables into a few linear combinations or principal components (factors), and is thus widely used in index number generation. PCA extracts a common factor, in this case $F C I_{t}$, from a group of $p$ variables, $X_{t}$ :

$$
X_{t}=\beta F C I_{t}+U_{t}
$$

where $\boldsymbol{X}_{\boldsymbol{t}}$ is a vector of $p$ standardised financial variables, $\boldsymbol{\beta}$ is a $p \times m$ coefficient matrix, $\boldsymbol{F C} \boldsymbol{I}_{\boldsymbol{t}}$ is a vector of $m_{X} 1$ unobserved variables, and $\boldsymbol{U}_{\boldsymbol{t}}$ is a $p_{\boldsymbol{X}} 1$ error vector ${ }^{5}$.

Thompson, et al. (forthcoming) purge the FCI of any potential endogenous feedback effects, so as to ensure that it captures only information about pure financial shocks and not past economic activity, inflation or interest rate effects. They do this by regressing the estimated FCI on manufacturing production growth, inflation and the nominal 3 -month Treasury Bill rate. The estimated residuals of this regression are regarded as the purged FCI ${ }^{6}$.

Thompson, et al. (forthcoming) also address the issue of parameter non-constancy and structural breaks through the implementation of rolling-window estimation techniques. Thompson, et al. (forthcoming) tested different approaches to constructing an FCI, resulting in four alternative indices: a rollingwindow PCA estimation vs. a static PCA estimation, and for each of these, they tested whether to purge the index of endogenous feedback effects or not ${ }^{7}$. Given their evidence that the variables used to compile the FCI exhibit statistical relevance that varies over time ${ }^{8}$, they allow the weights assigned to the financial variables within the index to evolve over time by estimating a 120 -month rolling-FCI ${ }^{9}$. A rolling-FCI is also relevant when considering that not only the relative importance of the individual data series within the index is time-variant, but also the impact of the FCI on the real economy changes over time. The usefulness of this rolling-window estimation becomes more apparent when one considers that economic agents make decisions based only on the information they have available at a particular point in time. Koop and Potter (2007) and Bauwens, Koop, Korobilis and Rombouts (2011) higlight the negative consequences for inference and forecasting of ignoring instability in

\footnotetext{
${ }^{5}$ In this instance our FCI is the first extracted principal component, so $m=1$.

${ }^{6}$ Thompson, et al. (forthcoming) conducted this purging by using contemporaneous values of the macroeconomic variables. They tested the use of past values in the purging process, and found that there was no significant difference in the results. Due to the loss in sample size caused by lagging the macroeconomic variables, they rather used contemporaneous purging.

7 Thompson, et al. (forthcoming) also tested the approaches of a simple-weighted average and recursive PCA. These indices however did not present adequate qualitative results and were therefore not explored further.

${ }^{8}$ A Ludvigson and $\mathrm{Ng}$ (2009 and 2010) assessment of the relevance of the individual components of the FCI over 10-year sub-samples provided the impetus for testing the rolling-window approach.

${ }^{9}$ A host of alternative window sizes were tested in Thompson, et al. (forthcoming), but the 120-month rolling window presented the best results qualitatively and also in terms of in-sample forecast tests.
} 
macroeconomic and financial time series ${ }^{10}$, which leads them to advocate the use of change-point models.

The estimated rolling-window FCI can be viewed in Figure 2 in the Appendix, and shows graphically how well the index picks up recessions in the South African economy. Positive values of the FCI indicate "positive" financial conditions, and vice versa for "negative" financial conditions ${ }^{11}$.

\section{Econometric Methodology}

The forecast encompassing test used in this paper follows Rapach and Weber (2004), and more details on the econometric methodology can be found in that paper. We consider the unrestricted ARDL model:

$$
\sum_{i=1}^{h} \Delta y_{t+i}=\alpha+\sum_{i=0}^{q_{1}-1} \beta_{i} \Delta y_{t-i}+\sum_{i=0}^{q_{2}-1} \gamma_{i} x_{t-i}+\varepsilon_{t+h}
$$

where $y_{t}$ is the variable of interest to be forecasted (manufacturing growth, Treasury Bill yield and inflation), $q_{1}$ and $q_{2}$ are the ARDL lags, $x_{t}$ is one of the sixteen financial variables or the FCI, and $h$ is the forecast horizon (set to a maximum of 24 months in this instance) ${ }^{12}$. The following recursive procedure is used to simulate the out-of-sample forecasting ability of the individual financial data series and the FCI: First, we divide the total sample of $T$ observations into the in-sample period, spanning $R$ observations, and the out-of-sample period, spanning $P$ observations (in this instance, our out-of-sample period is 1986M01-2012M01).

We then compute an out-of-sample forecast from the unrestricted model, Equation (2), by estimating (2) using ordinary least squares (OLS) over the period $R$. Use the OLS parameter estimates and observations for $x_{R-i}\left(i=0, \ldots q_{1}-1\right)$ and $\Delta y_{R-i}\left(i=0, \ldots q_{2}-1\right)$ to construct a forecast for $z_{R+h}$ based on:

$$
\hat{z}_{1, R+h}=\hat{\alpha}_{1, R}+\sum_{i=0}^{q_{1}-1} \hat{\beta}_{1, R, i} \Delta y_{R-i}+\sum_{i=0}^{q_{2}-1} \hat{\gamma}_{1, R, i} x_{R-i}
$$

where $\hat{\alpha}_{1, R}, \hat{\beta}_{1, R, i}\left(i=0, \ldots q_{1}-1\right)$ and $\hat{\gamma}_{1, R, i}\left(i=0, \ldots q_{2}-1\right)$ are the OLS estimates of Equation (2)'s $\alpha$, $\beta_{i}\left(i=0, \ldots q_{1}-1\right)$ and $\gamma_{i}\left(i=0, \ldots q_{2}-1\right)$ respectively, using data from period $R$. The unrestricted forecast error is:

$$
\hat{u}_{1, R+h}=z_{R+h}-\hat{z}_{1, R+h}
$$

\footnotetext{
${ }^{10}$ Pesaran, Pettenuzzo and Timmermann (2006) list output growth, inflation, exchange rates, interest rates and stock returns as typical series suffering from structural breaks - all of which we use in this research.

${ }^{11}$ For a discussion and mapping of South African business cycle trends and the FCI, refer to Thompson et al. (forthcoming).

12 This model can be used to conduct a test of the in-sample forecasting ability of $\mathrm{x}_{\mathrm{t}}$ by running a Wald test with Ho: $\gamma_{0}=\cdots=\gamma_{q 2-1}=0$.

Rejection of the null hypothesis indicates that there is evidence of in-sample forecasting ability/Granger causality. See Thompson, et al. (forthcoming) for these in-sample results with respect to the FCI. Results pertaining to the individual financial series are available from the authors upon request.
} 
An out-of-sample forecast from a restricted model is then computed, which is equivalent to estimating Equation (2) by OLS with $\gamma_{0}=\cdots=\gamma_{q_{2}-1}=0$ over the period $R$. From this we formulate a forecast:

$$
\hat{z}_{0, R+h}=\hat{\alpha}_{0, R}+\sum_{i=0}^{q_{1}-1} \hat{\beta}_{0, R, i} \Delta y_{R-i}
$$

where $\hat{\alpha}_{0, R}$ and $\hat{\beta}_{0, R, i}\left(i=0, \ldots q_{1}-1\right)$ are the OLS estimates of Equation (2)'s $\alpha$ and $\beta_{i}\left(i=0, \ldots q_{1}-1\right)$ respectively. The restricted forecast error is:

$$
\hat{u}_{0, R+h}=z_{R+h}-\hat{z}_{0, R+h}
$$

We generate a second set of forecasts by updating the procedure with one period, i.e. use data from period $R+1$. In other words, we form restricted and unrestricted forecasts for $z_{(R+1)+h}$, along with the restricted and unrestricted forecast errors, $\hat{u}_{1,(R+1)+h}$ and $\hat{u}_{0,(R+1)+h}$.

The process is repeated until the end of the sample, arising at two sets of $T-R-h+1$ recursive out-of-

sample forecast errors for the unrestricted and restricted models, namely $\left\{\hat{u}_{1, t+h}\right\}_{t=R}^{T-h}$ and $\left\{\hat{u}_{0, t+h}\right\}_{t=R}^{T-h}$. These forecast errors form the basis of the test statistics used in determining the most appropriate forecasting model (unrestricted vs. restricted; i.e. including financial variables or FCI vs. excluding these variables), which follow below.

We use five tests to compare the forecasts from the restricted and unrestricted models to determine whether the FCI and/or individual financial variables are relevant in forecasting the three macroeconomic variables. These tests are discussed below (Rapach and Weber (2004)).

\section{a. Theil's U Test}

If the root mean squared forecast error (RMSFE) of the unrestricted ARDL model (RMSFEUR) is less than the RMSFE of the restricted model (RMSFER), then this model is the "better" forecasting model with lower forecasting error. Therefore, if $U=\frac{R M S F E_{U R}}{R M S F E_{R}}$, a result of $U<1$ will indicate that the unrestricted ARDL model (i.e. the model including the financial variable or FCI as a predictor) forecasts are superior to those of the simple AR model ${ }^{13}$.

\section{b. MSE-T and MSE-F Tests}

In a more "formal" statistical manner, the MSFE of the two models is compared using the Diebold and Mariano (1995) and West (1996) statistic. The loss differential between the two models is calculated as:

$$
\hat{d}_{t+h}=\hat{u}_{0, t+h}^{2}-\hat{u}_{1, t+h}^{2}
$$

while:

$$
\bar{d}=(T-R-h+1)^{-1} \sum_{t=R}^{T-h} \hat{d}_{t+h}=\widehat{M S F E_{0}}-\widehat{M S F} E_{1}
$$

\footnotetext{
${ }^{13}$ Strictly speaking, Theil's $U$ uses a random walk model as a benchmark. In our applications, we follow Rapach and Weber (2004) in using the AR model as benchmark, but we still refer to the ratio of the RMSFEs from the restricted and unrestricted models as Theil's $\underline{\mathrm{U}}$.
} 
and:

$$
\hat{S}_{d d}=\sum_{j=-J}^{J} K\left(\frac{j}{J}\right) \hat{\Gamma}_{d d}(j)
$$

where:

$$
\hat{\Gamma}_{d d}(j)=(T-R-h+1)^{-1} \sum_{t=R+j}^{T-h}\left(\hat{d}_{t+h}-\bar{d}\right)\left(\hat{d}_{t+h-j}-\bar{d}\right)
$$

and, in line with Clark and McCracken (2004), the Bartlett kernel is used, $K\left(\frac{j}{J}\right)=1-\left[\frac{j}{J+1}\right]$, with $J=[1.5 h]$ for $h>1$ and $\hat{S}_{d d}=\hat{\Gamma}_{d d}(0)$ for $h=1$. The test statistic is represented as:

$$
M S E-T=(T-R-h+1)^{-0.5} \cdot \bar{d} \cdot \widehat{S}_{d d}^{-0.5}
$$

McCracken's (2007) variation of this statistic is:

$$
M S E-F=(T-R-h+1) \cdot \bar{d} / \widehat{M S F E} E_{1}
$$

where:

$$
\widehat{M S F E}_{1}=(T-R-h+1)^{-1} \sum_{t=R}^{T-h} \widehat{u}_{1, t+h}^{2}
$$

Inference of $M S E-T$ and $M S E-F$ is, as recommended by Clark and McCracken (2004), based on a bootstrapping procedure ${ }^{14}$ along the lines of Kilian (1999); and tests the null hypothesis of equal forecasting ability between the restricted and unrestricted models.

\section{c. ENC-T and ENC-NEW Tests}

Another way to compare forecasts between alternative models is based on the concept of forecast encompassing. Using the out-of-sample forecasts for the unrestricted (Equation (3)) and restricted (Equation (5)) models, a convex combination of the two, $z_{t+h}$, can be treated as an optimal composite out-of-sample forecast:

$$
\hat{z}_{c, t+h}=\lambda \hat{z}_{1, t+h}+(1-\lambda) \hat{z}_{0, t+h}
$$

where $0 \leq \lambda \leq 1$. If $\lambda=0$, then the restricted model's forecast encompasses the unrestricted model's forecast; i.e. the FCI or financial variables are not relevant in forecasting $y_{t}$. The null hypothesis of $H_{0}$. $\lambda=0$ (the restricted AR out-of-sample forecast encompasses the unrestricted ARDL out-of-sample forecast) is tested using the following statistic (Harvey et al. (1998)):

$$
E N C-T=(T-R-h+1)^{0.5} \cdot \bar{c} \cdot \widehat{S}_{c c}^{-0.5}
$$

where:

\footnotetext{
${ }_{14}$ The MSE-T and MSE-F statistics are assumed to be asymptotically normally distributed (West, 1996). However McCracken (2007) shows that they have a non-standard asymptotic distribution at $h=1$ when comparing nested models' forecasts - as is the case in this application and that the distribution is in fact a function of stochastic integrals of quadratics of Brownian motion for $M S E-T$, and a function of stochastic integrals of Brownian motion for MSE-F. Clark and McCracken (2004) similarly show that the limiting distribution is also non-standard for $h$ $>1$ when comparing nested models' forecasts. Therefore bootstrapped inference as proposed in Kilian (1999) is recommended.
} 


$$
\hat{c}_{t+h}=\hat{u}_{0, t+h}\left(\hat{u}_{0, t+h}-\hat{u}_{1, t+h}\right)
$$

while:

$$
\bar{c}=(T-R-h+1)^{-1} \sum_{t=R}^{T-h} \hat{c}_{t+h}=\widehat{M S F} E_{0}-\widehat{M S F E} E_{1}
$$

and:

$$
\hat{S}_{c c}=\sum_{j=-J}^{J} K\left(\frac{j}{J}\right) \hat{\Gamma}_{c c}(j)
$$

where:

$$
\hat{\Gamma}_{c c}(j)=(T-R-h+1)^{-1} \sum_{t=R+j}^{T-h}\left(\hat{c}_{t+h}-\bar{c}\right)\left(\hat{c}_{t+h-j}-\bar{c}\right)
$$

and, once again, the Bartlett kernel is used: $K\left(\frac{j}{J}\right)=1-\left[\frac{j}{J+1}\right]$, with $J=[1.5 h]$ for $h>1$ and $\hat{S}_{c c}=$ $\hat{\Gamma}_{c c}(0)$ for $h=1$. Clark and McCracken's (2001) variation of this statistic is:

$$
E N C-N E W=(T-R-h+1) \cdot \bar{c} / \widehat{M S F E} E_{1}
$$

These $E N C$ test statistics are essentially based on the difference between the variance of the restricted model's forecast errors, and the covariance of the restricted and unrestricted models' forecast errors. As with the MSE statistics, inference here is also based on bootstrapped parameters ${ }^{15}$.

Clark and McCracken $(2001,2004)$ in Rapach and Weber (2004) show that these four test statistics above have good size properties (when based on bootstrapped inference); and that the power of the tests can be ranked as follows (most to least powerful) ${ }^{16}: E N C-N E W, E N C-T, M S E-F$ and $M S E-T$.

\section{d. Bootstrapping Procedure}

The bootstrapping procedure used to enable inference of these test statistics (from Rapach and Weber, 2004) is Clark and McCracken's (2007) version of Kilian (1999). Suppose, under Ho. the financial variable $x_{t}$ has no forecasting power with respect to $y_{t}$, that:

$$
\Delta y_{t}=a_{0}+\sum_{i=1}^{p_{1}} a_{i} \Delta y_{t-i}+e_{1, t}
$$

and:

$$
x_{t}=b_{0}+\sum_{i=1}^{p_{2}} b_{i} \Delta y_{t-i}+\sum_{i=1}^{p_{3}} c_{i} x_{t-i}+e_{2, t}
$$

where the disturbance vector, $e_{t}=\left(e_{1, t}, e_{2, t}\right)^{\prime}$, is independently and identically distributed with covariance matrix $\Sigma$. The recursive procedure used in conducting the bootstrapping used in this paper (from Rapach and Weber, 2004:721-722) is as follows. Equations (21) and (22) are estimated by OLS, using all available observations with lag orders $p_{1}, p_{2}$ and $p_{3}$ selected using the AIC. The OLS residuals

\footnotetext{
${ }^{15}$ Clark and McCracken (2001) show that for nested models and for $h=1, E N C$ - $T$ has a non-standard limiting distribution; while $E N C$ - $N E W$ has a non-standard asymptotic distribution. For $h>1$ in nested models, Clark and McCracken (2004) show that $E N C-T$ and $E N C-N E W$ have non-standard asymptotic distributions. Thus, bootstrapped inference is once again recommended.

${ }^{16}$ The authors use extensive Monte Carlo simulations with nested models to ascertain these properties.
} 
are $\left\{\hat{e}_{t}=\left(\hat{e}_{1, t}, \hat{e}_{2, t}\right)^{\prime}\right\}_{t=1}^{T}$, and from these, a random draw (with replacement) is taken $T+50$ times, resulting in a pseudo-series of disturbance terms, $\left\{\hat{e}_{t}^{*}\right\}_{t=1}^{T+50}$.

A pseudo-sample of $T+50$ observations for $\Delta y_{t}$ and $x_{t}$, represented as $\left\{\Delta y_{t}^{*}, x_{t}^{*}\right\}_{t=1}^{T+50}$, is built up using Equations (21) and (22), the OLS parameter estimates and $\left\{\hat{e}_{t}^{*}\right\}_{t=1}^{T+50}$ (setting the initial lagged observations for $\Delta y_{t}$ and $x_{t}$ equal to 0 ). The first $50-p$ transient start-up observations (where $\left.p=\max \left\{p_{1}, p_{2}, p_{3}\right\}\right)$ are dropped to randomise the initial $\Delta y_{t}$ and $x_{t}$ observations, resulting in a pseudo-sample of $T+p$ observations, which is the same size as the original sample.

Each of the four test statistics described in Equations (11), (12), (15) and (20) are calculated 500 times, resulting in empirical distributions for these statistics. The $p$-value for each is the proportion of the bootstrapped statistic greater than the original statistic.

The estimated out-of-sample test statistics for the FCI are reported in Table 7 in the Appendix, and are summarised along with the results for all sixteen financial variables in 0 , 5 .band Table 4 below. The results are based on the Akaike Information Criterion (AIC) and are for forecast horizons of 1, 3, 6, 9, $12,15,18,21$ and 24 months. Values for $q_{1}$ and $q_{2}$ are considered from 0 up to 24 . The results are representative of the out-of-sample period of 1986M01-2012M01. Similar results for the periods 1973M01-2012M01 and 2000M01-2012M01 are available upon request.

\section{Empirical Results ${ }^{17}$}

\section{a. Out-of-Sample Forecasting Performance}

Table 1 reports for each variable the horizon at which that variable has significant forecasting ability for output growth according to the tests outlined above. 0 and $b$ show the same for the forecasting ability of inflation and the Treasury Bill rate respectively. Table 1 shows that the estimated FCI is a significant out-of-sample predictor of manufacturing output growth at all horizons (when considering the $E N C-N E W$ and $E N C$-T statistics, the two most powerful statistics). Share prices, house prices, M3 growth, the term spread, government bond volatility and private sector credit extension also have good out-of-sample forecasting ability at multiple horizons; while dividend yields appear to have weaker ability (i.e. at only the one month horizon).

In the case of inflation (0), the FCI exhibits forecasting ability at multiple horizons, but this time according to the less powerful $M S E-F$ and $M S E-T$ tests. Strong out-of-sample forecasting ability is attributed to share prices, the Rand-Dollar exchange rate, the Federal Funds rate, M3 growth, mortgage and bill spreads and private sector credit extension. House prices have weaker forecasting ability.

The FCI is again a strong out-of-sample predictor at multiple horizons in b, this time of the Treasury Bill yield. House prices, the Rand-Dollar exchange rate, M3 growth, bond and term spreads, house price volatility and private sector credit extension are also strong predictors of the Treasury Bill at

\footnotetext{
${ }^{17}$ Our results are obtained using codes written by David E. Rapach, which are available for download from http://sites.slu.edu/ rapachde/home/research.
} 
multiple horizons; while dividend yields and government bond volatility exhibit predictability at either shorter horizons or according to the $M S E-F$ and $M S E-T$ tests only.

Table 1. Out-of-sample forecasting performance, dependent variable: Manufacturing production growth

\begin{tabular}{|c|c|c|c|c|}
\hline \multirow{2}{*}{$\begin{array}{l}\text { Independent variable } \\
x_{t} \text { is... }\end{array}$} & \multicolumn{4}{|c|}{...significant according to: } \\
\hline & $\begin{array}{l}\text { MSE-T (for } h \\
\text { horizons) }\end{array}$ & MSE-F (for $h$ horizons) & $\begin{array}{l}\text { ENC-T (for } h \\
\text { horizons) }\end{array}$ & $\begin{array}{l}\text { ENC-NEW (for } h \\
\text { horizons) }\end{array}$ \\
\hline FCI & $0.392^{*}(\mathrm{~h}=6)$ & $\begin{array}{l}15.121^{* *}(h=6) \\
9.176^{*}(h=9)\end{array}$ & $\begin{array}{l}1.351^{*}(\mathrm{~h}=1) ; 1.585^{*} \\
(\mathrm{~h}=3) ; 1.752^{* *}(\mathrm{~h}=6) \\
2.068^{* *}(\mathrm{~h}=9) ; 1.974^{* *} \\
(\mathrm{~h}=12)\end{array}$ & $\begin{array}{l}9.376^{* * *}(\mathrm{~h}=1) ; \\
23.158^{* * *}(\mathrm{~h}=3) ; \\
36.250^{* * *}(\mathrm{~h}=6) ; \\
40.079^{* * *}(\mathrm{~h}=9) ; \\
28.372^{* *}(\mathrm{~h}=12)\end{array}$ \\
\hline All-share index & $0.624^{* *}(\mathrm{~h}=1)$ & $\begin{array}{l}4.116^{* * *}(\mathrm{~h}=1) ; 2.189^{* *} \\
(\mathrm{~h}=3)\end{array}$ & $1.727^{* *}(\mathrm{~h}=1)$ & $\begin{array}{l}5.841^{* *}(\mathrm{~h}=1) ; 3.274^{*} \\
(\mathrm{~h}=3) ; 2.418^{*}(\mathrm{~h}=6) ; \\
1.890^{*}(\mathrm{~h}=9)\end{array}$ \\
\hline House price index & $0.647^{*}(\mathrm{~h}=3)$ & $\begin{array}{l}1.566^{* *}(\mathrm{~h}=1) ; 7.478^{* *} \\
(\mathrm{~h}=3)\end{array}$ & $\begin{array}{l}1.672^{* *}(\mathrm{~h}=1) ; 2.002^{* *} \\
(\mathrm{~h}=3) ; 1.242^{*}(\mathrm{~h}=6)\end{array}$ & $\begin{array}{l}6.323^{* * *}(\mathrm{~h}=1) ; 11.635^{* *} \\
(\mathrm{~h}=3) ; 10.762^{* *}(\mathrm{~h}=6) ; \\
13.798^{*}(\mathrm{~h}=9)\end{array}$ \\
\hline Dividend yields & - & - & - & $3.614^{*}(\mathrm{~h}=1)$ \\
\hline M3 growth & - & - & $1.513^{*}(\mathrm{~h}=9)$ & $\begin{array}{l}3.123^{*}(\mathrm{~h}=1) ; 8.217^{* *} \\
(\mathrm{~h}=3) ; 13.619^{* *}(\mathrm{~h}=6) ; \\
21.348^{* *}(\mathrm{~h}=9) ; \\
19.330^{* *}(\mathrm{~h}=12)\end{array}$ \\
\hline Term spread & $1.389^{* *}(\mathrm{~h}=1)$ & $7.625^{* * *}(\mathrm{~h}=1)$ & $\begin{array}{l}2.640^{* * *}(\mathrm{~h}=1) ; 2.022^{* *} \\
(\mathrm{~h}=3) ; 2.531^{* *}(\mathrm{~h}=6)\end{array}$ & $\begin{array}{l}7.167^{* * *}(\mathrm{~h}=1) ; 12.690^{* *} \\
(\mathrm{~h}=3) ; 24.377^{* *}(\mathrm{~h}=6) ; \\
21.564^{*}(\mathrm{~h}=9)\end{array}$ \\
\hline $\begin{array}{l}\text { Government bond } \\
\text { volatility }\end{array}$ & $\begin{array}{l}0.725^{*}(\mathrm{~h}=1) ; 1.919^{* * *} \\
(\mathrm{~h}=3) ; 1.326^{* *}(\mathrm{~h}=6) ; \\
1.467^{* *}(\mathrm{~h}=9) ; 1.107^{* *} \\
(\mathrm{~h}=12)\end{array}$ & $\begin{array}{l}1.302^{* *}(\mathrm{~h}=1) ; 4.186^{* *} \\
(\mathrm{~h}=3) ; 3.692^{* *}(\mathrm{~h}=6) ; \\
7.095^{* *}(\mathrm{~h}=9) ; 3.792^{* *} \\
(\mathrm{~h}=12)\end{array}$ & $\begin{array}{l}1.228^{*}(\mathrm{~h}=1) ; 2.167^{* *} \\
(\mathrm{~h}=3) ; 1.419^{*}(\mathrm{~h}=6) ; \\
1.890^{* *}(\mathrm{~h}=9) ; 1.610^{*} \\
(\mathrm{~h}=12)\end{array}$ & $2.492^{*}(\mathrm{~h}=3)$ \\
\hline $\begin{array}{l}\text { Private sector credit } \\
\text { extension }\end{array}$ & - & - & - & $\begin{array}{l}8.986^{* *}(\mathrm{~h}=6) ; 10.696^{* *} \\
(\mathrm{~h}=9) ; 9.099^{*}(\mathrm{~h}=12)\end{array}$ \\
\hline
\end{tabular}


Table 2. Out-of-sample forecasting performance, dependent variable: Inflation

\begin{tabular}{|c|c|c|c|c|}
\hline \multirow{2}{*}{$\begin{array}{l}\text { Independent variable } \\
x_{t} \text { is... }\end{array}$} & \multicolumn{4}{|c|}{...significant according to: } \\
\hline & MSE-T for $h$ horizons & MSE-F for $h$ horizons & ENC-T for $h$ horizons & $\begin{array}{l}\text { ENC-NEW for } h \\
\text { horizons }\end{array}$ \\
\hline FCI & $\begin{array}{l}0.538^{*}(\mathrm{~h}=9) ; 0.967^{* *} \\
(\mathrm{~h}=12)\end{array}$ & $8.446^{*}(\mathrm{~h}=12)$ & - & - \\
\hline All-share index & $\begin{array}{l}0.569^{*}(\mathrm{~h}=6) ; 1.561^{* * *} \\
(\mathrm{~h}=9) ; 1.706^{* * *}(\mathrm{~h}=12)\end{array}$ & $h=6,9,12$ & $\begin{array}{l}2.003^{* *}(\mathrm{~h}=9) ; 2.049^{* *} \\
(\mathrm{~h}=12)\end{array}$ & $9.316^{* *}(\mathrm{~h}=12)$ \\
\hline House price index & - & $3.729^{*}(\mathrm{~h}=1)$ & $2.697^{*}(\mathrm{~h}=1)$ & $17.229^{*}(\mathrm{~h}=1)$ \\
\hline Exchange rate & $\begin{array}{l}0.371^{*}(\mathrm{~h}=3) ; 0.890^{* *} \\
(\mathrm{~h}=6) ; 1.017^{* *}(\mathrm{~h}=9) ; \\
0.932^{*}(\mathrm{~h}=12)\end{array}$ & $\begin{array}{l}9.050^{* * *}(\mathrm{~h}=3) ; \\
31.795^{* * *}(\mathrm{~h}=6) ; \\
42.585^{* * *}(\mathrm{~h}=9) ; \\
34.440^{* * *}(\mathrm{~h}=12)\end{array}$ & $\begin{array}{l}1.122^{*}(\mathrm{~h}=1) ; 1.759^{* *} \\
(\mathrm{~h}=3) ; 1.873^{* *}(\mathrm{~h}=6) ; \\
1.842^{* *}(\mathrm{~h}=9) ; 1.759^{* *} \\
(\mathrm{~h}=12)\end{array}$ & $\begin{array}{l}8.811^{* * *}(\mathrm{~h}=1) ; \\
23.322^{* * *}(\mathrm{~h}=3) ; \\
38.811^{* * *}(\mathrm{~h}=6) ; \\
43.652^{* * *}(\mathrm{~h}=9) ; \\
34.534^{* *}(\mathrm{~h}=12)\end{array}$ \\
\hline Federal funds rate & $\begin{array}{l}0.953^{*}(\mathrm{~h}=3) ; 1.522^{* *} \\
(\mathrm{~h}=6) ; 1.526^{*}(\mathrm{~h}=9) ; \\
1.779^{* *}(\mathrm{~h}=12)\end{array}$ & $\begin{array}{l}13.944^{* *}(h=3) ; 35.683 \\
(h=6) ; 46.819^{* *}(h=9) ; \\
65.368^{* *}(h=12)\end{array}$ & $\begin{array}{l}2.205^{*}(h=3) ; 2.248^{*} \\
(h=6) ; 2.128^{*}(h=9) ; \\
2.230^{*}(h=12)\end{array}$ & $\begin{array}{l}5.369^{*}(\mathrm{~h}=1) ; 16.494^{* *} \\
(\mathrm{~h}=3) ; 29.049^{* *}(\mathrm{~h}=6) ; \\
37.731^{*}(\mathrm{~h}=9) ; 49.654^{* *} \\
(\mathrm{~h}=12)\end{array}$ \\
\hline M3 growth & $\begin{array}{l}1.176^{* *}(\mathrm{~h}=6) ; 1.586^{* *} \\
(\mathrm{~h}=9) ; 2.163^{* *}(\mathrm{~h}=12)\end{array}$ & $\begin{array}{l}8.984^{* *}(\mathrm{~h}=6) ; 28.379^{* *} \\
(\mathrm{~h}=9) ; 40.689^{* *}(\mathrm{~h}=12)\end{array}$ & $\begin{array}{l}2.028^{* *}(\mathrm{~h}=6) ; 3.128^{* *} \\
(\mathrm{~h}=9) ; 3.560^{* * *}(\mathrm{~h}=12)\end{array}$ & $\begin{array}{l}8.003^{*}(\mathrm{~h}=6) ; 32.157^{* *} \\
(\mathrm{~h}=9) ; 41.302^{* *}(\mathrm{~h}=12)\end{array}$ \\
\hline Mortgage spread & $\begin{array}{l}3.102^{* * *}(\mathrm{~h}=1) ; 2.351^{* * *} \\
(\mathrm{~h}=3) ; 2.136^{* * *}(\mathrm{~h}=6) ; \\
2.136^{* * *}(\mathrm{~h}=9) ; 2.265^{* * *} \\
(\mathrm{~h}=12)\end{array}$ & $\begin{array}{l}8.800^{* * *}(\mathrm{~h}=1) ; \\
11.613^{* * *}(\mathrm{~h}=3) ; 9.049^{* *} \\
(\mathrm{~h}=6) ; 13.376^{*}(\mathrm{~h}=9) ; \\
10.154^{*}(\mathrm{~h}=12)\end{array}$ & $\begin{array}{l}3.393^{* * *}(\mathrm{~h}=1) ; 2.577^{* * *} \\
(\mathrm{~h}=3) ; 2.372^{* *}(\mathrm{~h}=6) ; \\
2.302^{* * *}(\mathrm{~h}=9) ; 2.529^{* *} \\
(\mathrm{~h}=12)\end{array}$ & $\begin{array}{l}4.932^{* *}(\mathrm{~h}=1) ; 6.583^{*} \\
(\mathrm{~h}=3)\end{array}$ \\
\hline Bill spread & $\begin{array}{l}1.507^{* * *}(\mathrm{~h}=1) ; 1.082^{* *} \\
(\mathrm{~h}=3) ; 0.860^{*}(\mathrm{~h}=6) ; \\
1.053^{* *}(\mathrm{~h}=9) ; 1.176^{* *} \\
(\mathrm{~h}=12)\end{array}$ & $\begin{array}{l}4.306^{* *}(\mathrm{~h}=1) ; 8.282^{* *} \\
(\mathrm{~h}=3) ; 7.570^{*}(\mathrm{~h}=6) ; \\
9.538^{*}(\mathrm{~h}=9) ; 11.634^{*} \\
(\mathrm{~h}=12)\end{array}$ & $\begin{array}{l}2.033^{* *}(\mathrm{~h}=1) ; 1.542^{*} \\
(\mathrm{~h}=3) ; 1.498^{*}(\mathrm{~h}=9) ; \\
1.639^{*}(\mathrm{~h}=12)\end{array}$ & $\begin{array}{l}2.958^{*}(h=1) ; 6.165^{*} \\
(\mathrm{~h}=3)\end{array}$ \\
\hline $\begin{array}{l}\text { Private sector credit } \\
\text { extension }\end{array}$ & $0.945^{*}(\mathrm{~h}=12)$ & $\begin{array}{l}10.380 *(h=9) ; 17.574^{*} \\
(h=12)\end{array}$ & $2.220^{*}(\mathrm{~h}=12)$ & $\begin{array}{l}4.821^{*}(\mathrm{~h}=1) ; 7.202^{*} \\
(\mathrm{~h}=3) ; 13.833^{*}(\mathrm{~h}=6) ; \\
19.498^{*}(\mathrm{~h}=12)\end{array}$ \\
\hline
\end{tabular}

\section{b. Data-Mining}

The results in Table 1, 0 and $\mathrm{b}$ indicate that there is significant evidence of out-of-sample forecasting ability for the FCI and for many financial variables with respect to output growth, inflation and the Treasury Bill yield. However, where much of the research on out-of-sample forecast encompassing ends at this point, we decide to consider the possibility that, due to the large number of variables considered (17 including the FCI), we may have engaged in data-mining. Therefore, in line with Rapach and Weber (2004), we test the robustness of our results by controlling for data mining using the Inoue and Kilian (2004) bootstrapping procedure ${ }^{18}$.

Until this point, the null hypothesis has been that none of the 16 financial variables has out-of-sample forecasting ability, against an alternative of at least one variable having forecasting power. Suppose now that the null hypothesis is $H o$. the largest $E N C-N E W$ statistic across the 16 financial variables equals zero, against an alternative hypothesis that it is larger than zero.

\footnotetext{
${ }^{18}$ Hoover and Perez (2000) present the case that if data-mining 'must' be engaged in, then statistical inference should be adjusted so that critical values are made to be stricter.
} 


$$
\Delta y_{t}=a_{0}+\sum_{i=1}^{p_{1}} a_{i} \Delta y_{t-i}+e_{1, t}
$$

and:

$$
x_{t, j}=b_{0, j}+\sum_{i=1}^{p_{2, j}} b_{i, j} \Delta y_{t-i}+\sum_{i=1}^{p_{3, j}} c_{i, j} x_{t-i, j}+e_{2, t, j}, \quad j=1, \ldots 16^{19}
$$

where the disturbance vector, $e_{t}=\left(e_{1, t}, e_{2, t, 1}, \ldots, e_{2, t, 16}\right)^{\prime}$, is independently and identically distributed with covariance matrix $\Sigma$.

\begin{tabular}{|c|c|c|c|c|}
\hline \multirow{2}{*}{$\begin{array}{l}\text { Independent variable } \\
\boldsymbol{x}_{t} \text { is... }\end{array}$} & \multicolumn{4}{|c|}{...significant according to: } \\
\hline & MSE-T for $h$ horizons & MSE-F for $h$ horizons & ENC-T for $h$ horizons & $\begin{array}{l}\text { ENC-NEW for } h \\
\text { horizons }\end{array}$ \\
\hline FCI & - & - & - & $9.480^{*}(\mathrm{~h}=9)$ \\
\hline House price index & - & - & - & $\begin{array}{l}4.513^{* *}(\mathrm{~h}=1) ; 9.302^{* *} \\
(\mathrm{~h}=3) ; 21.480^{* *}(\mathrm{~h}=6) ; \\
27.716^{* * *}(\mathrm{~h}=9) ; \\
28.498^{* *}(\mathrm{~h}=12)\end{array}$ \\
\hline Exchange rate & - & - & $1.336^{*}(\mathrm{~h}=1)$ & $\begin{array}{l}10.923^{* * *}(\mathrm{~h}=1) ; \\
10.957^{* *}(\mathrm{~h}=3) ; \\
10.075^{* *}(\mathrm{~h}=6) ; 8.409^{* *} \\
(\mathrm{~h}=9) ; 8.890^{*}(\mathrm{~h}=12)\end{array}$ \\
\hline Dividend yields & $\begin{array}{l}1.698^{* *}(\mathrm{~h}=3) ; 1.578^{* *} \\
(\mathrm{~h}=6) ; 0.568^{*}(\mathrm{~h}=9) \\
0.470^{*}(\mathrm{~h}=12)\end{array}$ & $\begin{array}{l}7.456^{* *}(\mathrm{~h}=3) ; 11.609^{* *} \\
(\mathrm{~h}=6)\end{array}$ & $\begin{array}{l}2.071^{* *}(\mathrm{~h}=3) ; 2.017^{* *} \\
(\mathrm{~h}=6)\end{array}$ & - \\
\hline M3 growth & $\begin{array}{l}0.699^{*}(\mathrm{~h}=6) ; 0.837^{*} \\
(\mathrm{~h}=9) ; 0.738^{* *}(\mathrm{~h}=12)\end{array}$ & $\begin{array}{l}2.809^{* *}(\mathrm{~h}=6) ; 34.416^{* * *} \\
(\mathrm{~h}=9) ; 33.650^{* * *}(\mathrm{~h}=12)\end{array}$ & $\begin{array}{l}1.466^{*}(\mathrm{~h}=6) ; 3.454^{* * *} \\
(\mathrm{~h}=9) ; 3.421^{* * *}(\mathrm{~h}=12)\end{array}$ & $\begin{array}{l}74.039^{* * *}(\mathrm{~h}=9) \\
77.570^{* * *}(\mathrm{~h}=12)\end{array}$ \\
\hline Bond spread & $\begin{array}{l}1.076^{* *}(\mathrm{~h}=3) ; 0.961^{*} \\
(\mathrm{~h}=6)\end{array}$ & $\begin{array}{l}5.643^{* *}(\mathrm{~h}=3) ; 8.305^{*} \\
(\mathrm{~h}=6)\end{array}$ & $\begin{array}{l}2.172^{* *}(\mathrm{~h}=3) ; 2.018^{*} \\
(\mathrm{~h}=6)\end{array}$ & $\begin{array}{l}5.739^{*}(\mathrm{~h}=3) ; 8.826^{*} \\
(\mathrm{~h}=6) ; 11.403^{*}(\mathrm{~h}=9) \\
18.026^{*}(\mathrm{~h}=12)\end{array}$ \\
\hline $\begin{array}{l}\text { Government bond } \\
\text { volatility }\end{array}$ & - & - & - & $3.607^{* *}(\mathrm{~h}=1)$ \\
\hline House price volatility & $\begin{array}{l}0.843^{*}(\mathrm{~h}=6) ; 1.731^{* * *} \\
(\mathrm{~h}=9) ; 1.019^{*}(\mathrm{~h}=12)\end{array}$ & $\begin{array}{l}1.047^{*}(\mathrm{~h}=1) ; 7.889^{* *} \\
(\mathrm{~h}=9) ; 6.188^{*}(\mathrm{~h}=12)\end{array}$ & $\begin{array}{l}1.793^{* *}(\mathrm{~h}=1) ; 1.523^{*} \\
(\mathrm{~h}=6) ; 2.158^{* *}(\mathrm{~h}=9) ; \\
1.563^{*}(\mathrm{~h}=12)\end{array}$ & $6.180^{* *}(\mathrm{~h}=1)$ \\
\hline $\begin{array}{l}\text { Private sector credit } \\
\text { extension }\end{array}$ & - & - & $\begin{array}{l}1.571^{* *}(\mathrm{~h}=3) ; 2.008^{* *} \\
(\mathrm{~h}=6) ; 2.018^{* *}(\mathrm{~h}=9) \\
2.057^{* *}(\mathrm{~h}=12)\end{array}$ & $\begin{array}{l}18.252^{* * *}(\mathrm{~h}=3) ; \\
36.096^{* * *}(\mathrm{~h}=6) ; \\
41.523^{* * *}(\mathrm{~h}=9) ; \\
40.932^{* * *}(\mathrm{~h}=12)\end{array}$ \\
\hline
\end{tabular}

Table 3. Out-of-sample forecasting performance, dependent variable: Treasury Bill

Notes for Table 1 to b: $M S E-T$ and $M S E-F$ test the null hypothesis of equal forecasting ability between the restricted and unrestricted models. $E N C-T$ and $E N C-N E W$ test the null hypothesis that the restricted model forecast encompasses the unrestricted model forecast. ${ }^{* * * * * * *}$ indicates rejection of the null hypothesis (i.e. the financial variables of the unrestricted model have out-of-sample forecasting ability) at the $1 / 5 / 10 \%$ level of significance.

For a discussion on the recursive procedure used to conduct the bootstrapping exercise, see Rapach and Weber (2004:733-734). Each of the four out-of-sample test statistics previously described in Equations (11), (12), (15) and (20) are then calculated for each of the $x_{t, j}$ variables $(j=1, \ldots 16)$, and the

\footnotetext{
${ }^{19}$ Note that in running the data-mining programs, we exclude the FCI as an explanatory variable, since it contains the information of the 16 financial variables.
} 
maximum of each of the out-of-sample statistics across the 16 predictors is stored. This process is repeated 500 times, resulting in empirical distributions for these statistics, which are used to compute $10 \%, 5 \%$ and $1 \%$ critical values for each of the maximal statistics.

The data-mining-robust critical values are reported in Table 8, Table 9 and Table 10 in the Appendix, and Table 4 shows which variables are now significant out-of-sample forecasters of manufacturing production growth, inflation and the Treasury Bill yield, after data-mining is accounted for. As can be seen from the Table, the number of predictors for each macroeconomic variable has decreased significantly due to the data-mining adjustments. Furthermore, the FCI is now regarded as an out-ofsample predictor for manufacturing output growth only.

Table 4. Out-of-sample forecasting performance after data-mining adjustments

\begin{tabular}{|c|c|c|c|c|c|}
\hline \multirow{2}{*}{$\begin{array}{l}\text { Independent variable } \\
X_{t} \text { is... }\end{array}$} & \multicolumn{4}{|c|}{...significant according to: } & \multirow{2}{*}{$\begin{array}{l}\text {...in forecasting } y_{t} \\
\text { macroeconomic } \\
\text { variable }\end{array}$} \\
\hline & $\begin{array}{l}M S E-T \text { for } h \\
\text { horizons... }\end{array}$ & $\begin{array}{l}M S E-F \text { for } h \\
\text { horizons... }\end{array}$ & $\begin{array}{l}E N C-T \text { for } h \\
\text { horizons... }\end{array}$ & $\begin{array}{l}E N C-N E W \text { for } h \\
\text { horizons... }\end{array}$ & \\
\hline FCI & & & & $h=1,3,6$ & \multirow{3}{*}{$\begin{array}{l}\text { Manufacturing } \\
\text { production } \\
\text { growth }\end{array}$} \\
\hline SPREADN_TERM & & $\mathrm{h}=1$ & $\mathrm{~h}=1$ & & \\
\hline GBINDEX_VOL & $\mathrm{h}=3$ & & & & \\
\hline D_LHOUSEP & & & & $\mathrm{h}=1$ & \multirow{5}{*}{ Inflation } \\
\hline D_LRD & & & & $h=3,6$ & \\
\hline FED & & $\mathrm{h}=6,9,12$ & & & \\
\hline M3_GR & $\mathrm{h}=12,15$ & & $\mathrm{~h}=9,12$ & & \\
\hline SPREADN_MORT & $\mathrm{h}=1,3,6,9,12$ & $\mathrm{~h}=1$ & $\mathrm{~h}=1$ & & \\
\hline M3_GR & & $\mathrm{h}=9$ & $\mathrm{~h}=9,12$ & $\mathrm{~h}=9,12$ & \multirow{2}{*}{ Treasury Bill } \\
\hline D_LPSCE & & & & $\mathrm{h}=6,9$ & \\
\hline
\end{tabular}

Notes: $M S E-T$ and $M S E-F$ test the null hypothesis of equal forecasting ability between the restricted and unrestricted models. $E N C-T$ and $E N C-N E W$ test the null hypothesis that the restricted model forecast encompasses the unrestricted model forecast. The test statistics in this Table are the same as in Table 1, 0 and b-the bootstrapped critical values used for inference (see Table 8 to Table 10 in the appendices) are different.

\section{c. Predictor Significance}

The results above indicate that for the FCI and a number of the financial variables, a forecast of manufacturing production growth, inflation and the Treasury Bill yield generated by an ARDL model incorporating said financial variables, is superior to a simple AR forecasting model. However, these results do not provide insight as to how much the financial variables actually improve the forecasts highlighting the need to ascertain the "forecasting significance" of the financial variables ${ }^{20}$. Therefore, Table 5 provides the values of $\lambda$, the estimated weight of the unrestricted model in Equation (14)'s optimal composite out-of-sample forecast, for those variables in Table 4 above that "survived" the datamining adjustments according to the $E N C-T$ and $E N C-N E W$ statistics $^{21}$. Recall that $0 \leq \lambda \leq 1$, and if $\lambda=0$, then the restricted model's forecast encompasses the unrestricted model's forecast; i.e. the

\footnotetext{
${ }^{20}$ Rapach and Weber (2004) claim that this is essentially similar to establishing the economic significance of a parameter estimate (vs. the statistical significance).

${ }^{21}$ Note that results are presented only for the forecast horizons deemed significant in Table 5.
} 
financial variables are not relevant in forecasting $y_{t}$. Therefore, as $\lambda \rightarrow 1$, the unrestricted model's forecast is more important in generating the optimal composite forecast ${ }^{22}$.

The results shown in Table 5 indicate that the term spread is significantly quantitatively important in generating an optimal composite forecast of manufacturing production growth $(\lambda>0.9)$; whilst the FCI is less so (however the importance of the FCI increases as the horizon length increases, reaching $\lambda=0.6$ as $h=6)$. M3 growth is also significantly quantitatively important in generating an inflation forecast $(\lambda$ $>0.9)$; whilst house prices and the Rand-Dollar exchange rate are slightly less so $(\lambda \approx 0.6$ and $\lambda \approx 0.7$ respectively). M3 growth is again regarded as a relatively important predictor, this time for the Treasury Bill, with $\lambda \approx 0.7$ at various horizons. The smallest estimates of $\lambda$ are observed in the equation of private sector credit extension as a predictor of the Treasury Bill yield $(\lambda \approx 0.4)$.

Table 5. Least Squares Estimates of $\lambda$

\begin{tabular}{|c|c|c|c|c|c|}
\hline \multicolumn{6}{|c|}{ yt: Manufacturing production growth } \\
\hline$x_{t}: F C I$ & $h=1$ & $h=3$ & $h=6$ & & \\
\hline Theil's $U$ & 0.996 & 0.974 & 0.943 & & \\
\hline$\lambda$ & 0.266 & 0.472 & 0.629 & & \\
\hline${ }_{x t}:$ SPREADN_TERM & $h=1$ & & & & \\
\hline Theil's $U$ & 0.985 & & & & \\
\hline$\lambda$ & 0.977 & & & & \\
\hline \multicolumn{6}{|l|}{ yt: Inflation } \\
\hline$x_{t}: D \_L H O U S E P$ & $h=1$ & & & & \\
\hline Theil's $U$ & 0.978 & & & & \\
\hline$\lambda$ & 0.561 & & & & \\
\hline$x_{t}: D_{-} L R D$ & $h=3$ & $h=6$ & & & \\
\hline Theil's $U$ & 0.964 & 0.932 & & & \\
\hline$\lambda$ & 0.547 & 0.746 & & & \\
\hline$X t: M 3 \_G R$ & $h=9$ & $h=12$ & & & \\
\hline Theil's $U$ & 0.908 & 0.939 & & & \\
\hline$\lambda$ & 0.939 & 0.985 & & & \\
\hline \multicolumn{6}{|l|}{ yt: Treasury Bill yield } \\
\hline$x_{t}: M 3 \_G R$ & $h=9$ & $h=12$ & $h=15$ & $h=18$ & $h=21$ \\
\hline Theil's $U$ & 0.917 & 0.914 & 0.917 & 0.924 & 0.930 \\
\hline$\lambda$ & 0.705 & 0.691 & 0.694 & 0.702 & 0.752 \\
\hline$x_{t}: D \_L P S C E$ & $h=6$ & $h=9$ & $h=15$ & & \\
\hline Theil's $U$ & 0.973 & 0.967 & 0.958 & & \\
\hline$\lambda$ & 0.430 & 0.432 & 0.433 & & \\
\hline
\end{tabular}

Notes: If Theil's $\mathrm{U}<1$ then RMSFE of the unrestricted model is $<$ RMSFE of the restricted model, indicating the relevance of the individual financial variables as "forecasters" (i.e. lower Theil's $U$ values are preferable). $\lambda$ is the estimated weight of the unrestricted model's out-ofsample forecast in Equation (14), and is estimated with an intercept in Equation (14).

The $U$ statistics in all instances in Table 5 also show that the RMSFEs of the unrestricted optimal composite forecast models' forecasts are superior to (smaller than) the RMSFEs of the restricted benchmark AR models' forecasts.

\section{d. An Illustration as of 2012M02}

\footnotetext{
${ }^{22}$ Note that in certain instances for $x_{t}=$ M3 and $x_{t}=$ SPR_MORT, $\lambda$ was found to have inconsistent values (i.e. $>1$ ). We take the approach of Rapach and Weber (2004) who experienced similar issues in their research, and disregard these results.
} 
Figure 1 provides an illustration of the usefulness of the variables surviving the data-mining adjustment for forecasting manufacturing output growth, $y_{t}$, generated using the unrestricted ARDL model in Equation 2 as of 2012M02. $x_{t}$ represents the variables "surviving" the data-mining adjustments in Table 4, namely the FCI, the term spread, and government bond volatility. The forecasts are generated 11 months ahead for the period from $2012 \mathrm{M} 02$ to $2012 \mathrm{M} 12^{23}$. The figure shows that all three predictors present good forecasts of $y t$, and the RMSE statistics ${ }^{24}$ for the FCI (1.403), term spread (1.461) and government bond volatility (1.432) indicate that the FCI is the best predictor out of the three ${ }^{25}$.

\section{Figure 1. Forecasts of manufacturing output growth}

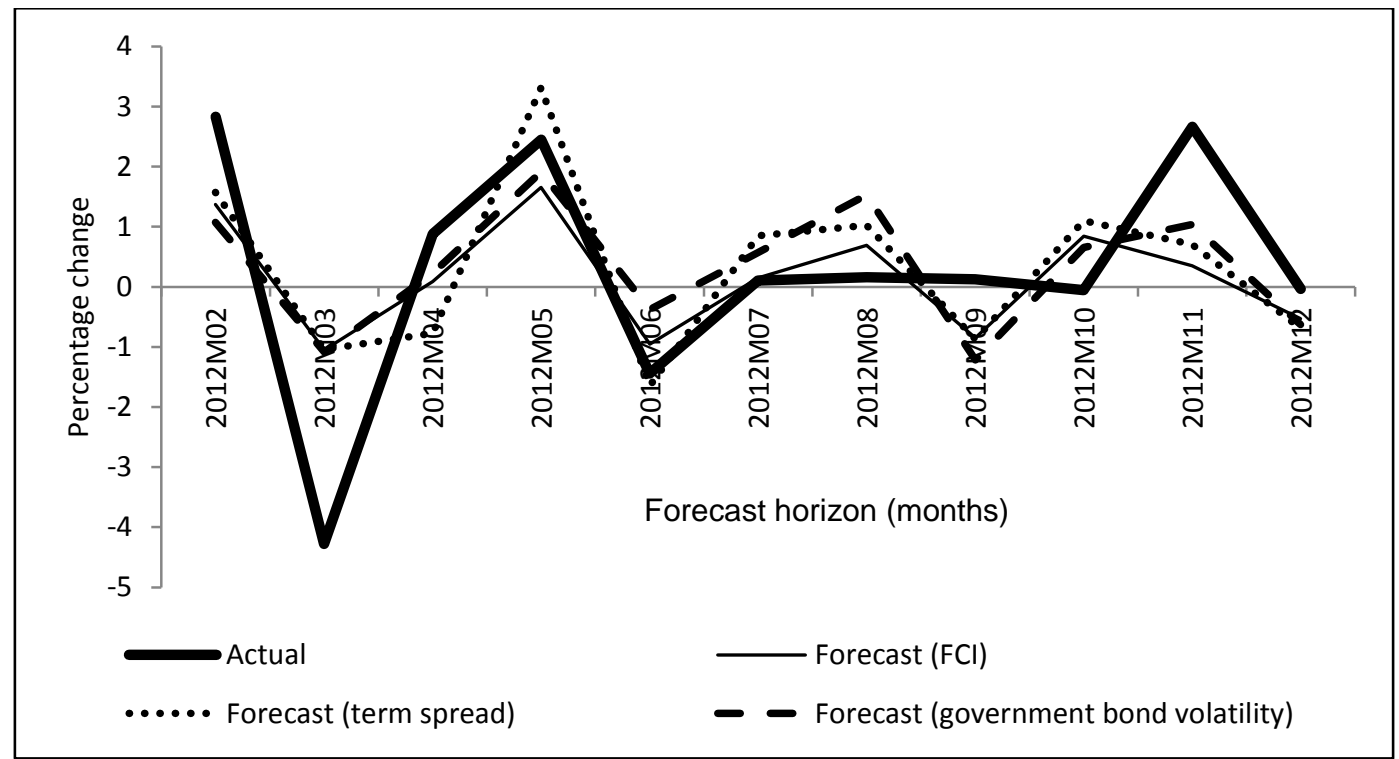

\section{Conclusions}

The objective of this paper was to test the out-of-sample forecasting ability of a 16-variable FCI constructed by Thompson, et al. (forthcoming) using rolling-window PCA, which was furthermore purged of the endogenous feedback effects of the macroeconomic variables of output growth, inflation and interest rates. The aim was to test whether the estimated FCI does better than its individual financial components in forecasting key macroeconomic variables, namely output growth, inflation and an interest rate. The forecast encompassing approach of Rapach and Weber (2004) was used, and four test statistics in particular were assessed. Inference based on these statistics was adjusted for the potential problem of data-mining using bootstrapping procedures, and it was found that the estimated FCI has out-of-sample forecasting ability with respect to manufacturing output growth at the one, three and six month horizons, while it has no predictive power for inflation and the Treasury bill yield.

\footnotetext{
${ }^{23}$ EX ante forecasting over this period is done by using the estimate of the model until 2012M01, and forecasting without updating the estimates.

24 The RMSE statistic is calculated as the square root of the average of the squares of the errors.

${ }^{25}$ A similar forecasting exercise is conducted over the period of the financial crisis (2007:12 - 2009:08 are the official recession dates in South Africa), and the FCI again has the best forecasting performance (RMSE $=2.138$; MAE $=1.638$ ), compared to government bond volatility $(\mathrm{RMSE}=2.652 ; \mathrm{MAE}=2.191)$ and the term spread $(\mathrm{RMSE}=2.734 ; \mathrm{MAE}=2.148)$.
} 
Furthermore, the $\lambda$ parameter on this FCI indicates relative 'strength' as an economic predictor, with a value of 0.6 at the 6 month horizon. An illustration of generating forecasts of manufacturing output growth using the FCI as of 2012M02 demonstrates the promise of this approach, with smaller RMSE statistics than alternative predictors of output. This therefore highlights the possibility of using the rolling-window estimated FCI as an early warning indicator for impending macroeconomic instability caused by deteriorating financial conditions.

\section{References}

Bauwens, L., Koop, G., Korobilis, D. \& Rombouts, J., 2011. A Comparison of Forecasting Procedures for Macroeconomic Series: The Contribution of Structural Break Models. CIRANO Scientific Series, Issue 2011s-13.

Clark, T. \& McCracken, M., 2001. Tests of Equal Forecast Accuracy and Forecast Encompassing for Nested Models. Journal of Econometrics, 105(1), pp. 85-110.

Clark, T. \& McCracken, M., 2004. Evaluating Long-Horizon Forecasts. University of MissouriColumbia Manuscript.

Clements, M.P. \& Harvey, D.I., 2007. Forecast combination and encompassing. In: Mills, T.C. \& Patterson, K. (eds) Palgrave Handbook of Econometrics: Vol 2 Applied Econometrics. Houndmills, Hampshire: Palgrave Macmillan Ltd.

Diebold, F. \& R.Mariano, 1995. Comparing Predictive Accuracy. Journal of Business and Economic Statistics, 13(2), pp. 253-263.

Harvey, D., Leybourne, S. \& Newbold, P., 1998. Tests for Forecast Encompassing. Journal of Business and Economic Statistics, 16(2), pp. 254-259.

Hoover, K. D. \& Perez, S. J., 2000. Three Attitudes Towards Data Mining. Journal of Economic Methodology, 7(2), pp. 195-210.

Inoue, A. \& Kilian, L., 2004. In-Sample or Out-of-Sample Tests of Predictability: Which One Should We Use?. Econometric Reviews, 23(4), pp. 371-402.

Kilian, L., 1999. Exchange Rates and Monetary Fundamentals: What Do We Learn from Long-Horizon Regressions?. Journal of Applied Econometrics, 14(5), pp. 491-510.

Kışınbay, T., 2007. The Use of Encompassing Tests for Forecast Combinations. IMF Working Paper, $\mathrm{WP} / 07 / 264$.

Koop, G. \& Potter, S., 2007. Estimation and Forecasting in Models with Multiple Breaks. Review of Economic Studies, Volume 74, pp. 763-789. 
Ludvigson, S. \& Ng, S., 2009. Macro Factors in Bond Risk Premia. The Review of Financial Studies, Volume 22(12), pp. 5027-5067.

Ludvigson, S. \& Ng, S., 2010. A Factor Analysis of Bond Risk Premia. In: A. Uhla \& D. Giles, eds. Handbook of Empirical Economics and Finance. Boca Raton: Chapman and Hall, pp. 313-372.

Mayes, D. \& Viren, M., 2001. Financial Conditions Indexes. Bank of Finland Discussion Papers, Volume 17/2001.

McCracken, M., 2007. Asymptotics for Out-of-Sample Tests of Granger Causality. Journal of Econometrics, 140(2), pp. 719-752.

Ng, S. \& Perron, P., 2001. Lag length selection and the construction of unit root tests with good size and power. Econometrica, 69(6), pp. 1519-54.

Ng, S. \& Perron, P., 2001. Lag length selection and the construction of unit root tests with good size and power. Econometrica, Volume 69(6), pp. 1519-54.

Pesaran, M., Pettenuzzo, D. \& Timmermann, A., 2006. Forecasting Time Series Subject to Multiple Structural Breaks. Review of Economic Studies, Volume 73, pp. 1057-1084.

Rapach, D. \& Weber, C., 2004. Financial Variables and the Simulated Out-of-Sample Forecastability of U.S. Output Growth Since 1985: An Encompassing Approach. Economic Enquiry, 42(4), pp. 717-738.

Stock, J. \& Watson, M., 2003. Forecasting Output and Inflation: The Role of Asset Prices. Journal of Economic Literature, 41(3), pp. 788-829.

Stock, J. \& Watson, M., 2003. Forecasting Output and Inflation: The Role of Asset Prices. Journal of Economic Literature, Volume 41(3), pp. 788-829.

Thoma, M.A. \& Gray, J.A., 1998. Financial Market Variables Do Not Predict Real Activity. Economic Inquiry, 36(4), pp. 522-539.

Thompson, K., Van Eyden, R. \& Gupta, R., Forthcoming. Identifying a Financial Conditions Index for South Africa. Studies in Economics and Finance.

West, K., 1996. Asymptotic Inference about Predictive Ability. Econometrica, 64(5), pp. 1067-1084. 


\section{Appendix}

Table 6. Variables used to construct and test the FCI

\begin{tabular}{|c|c|c|}
\hline \multicolumn{3}{|c|}{ Variables used to construct FCI } \\
\hline Name & Description & Transformation(s) \\
\hline ALSI_VOL & Stock exchange volatility (South Africa) & $\begin{array}{l}\text { Square of the first log difference } \\
\text { of the All-Share Index }\end{array}$ \\
\hline CONFUSN & University of Michigan US Consumer Sentiment Index & N/A \\
\hline D_LALSI & FTSE/JSE All-Share Index (South Africa) & $\begin{array}{l}\text { Seasonally adjusted, deflated by } \\
\text { South African CPI, first log } \\
\text { difference }\end{array}$ \\
\hline D_LHOUSEP & $\begin{array}{l}\text { Absa House Price Index (medium house size } 141 \mathrm{~m}^{2}- \\
\left.220 \mathrm{~m}^{2}\right) \text { (South Africa) }\end{array}$ & $\begin{array}{l}\text { Deflated by South African CPI, } \\
\text { first log difference }\end{array}$ \\
\hline D_LPSCE & Credit extended to domestic private sector (South Africa) & $\begin{array}{l}\text { Deflated by South African CPI, } \\
\text { first log difference }\end{array}$ \\
\hline D_LRD & Rand-US Dollar exchange rate & $\begin{array}{l}\text { Seasonally adjusted, deflated by } \\
\text { relative US-SA CPI, first log } \\
\text { difference }\end{array}$ \\
\hline D_LSP500 & S\&P500 Composite Price Index & $\begin{array}{l}\text { Seasonally adjusted, deflated by } \\
\text { US CPI, first log difference }\end{array}$ \\
\hline DIVN & $\begin{array}{l}\text { Johannesburg Stock Exchange dividend yield (South } \\
\text { Africa) }\end{array}$ & Seasonally adjusted \\
\hline FED & US Federal Funds market rate & Deflated by US CPI \\
\hline GBINDEX_VOL & Government bond volatility (South Africa) & $\begin{array}{l}\text { Square of the first log difference } \\
\text { of Government Bond Return } \\
\text { Index }\end{array}$ \\
\hline HOUSEP_VOL & House price volatility (South Africa) & $\begin{array}{l}\text { Square of the first log difference } \\
\text { of House Price Index }\end{array}$ \\
\hline M3_GR & $\begin{array}{l}\text { Month-on-month growth in M3 money supply }{ }^{26} \text { (South } \\
\text { Africa) }\end{array}$ & $\begin{array}{l}\text { Seasonally adjusted, deflated, } \\
\text { month-on-month rate of change }\end{array}$ \\
\hline SPREADN_BOND & $\begin{array}{l}\text { Long-term bond spread between Eskom Corporate Bond } \\
\text { yield and 10-year Government Bond yield (South Africa) }\end{array}$ & N/A \\
\hline SPREADN_MORT & $\begin{array}{l}\text { Mortgage spread between mortgage loan borrowing rate } \\
\text { and 3-month Treasury Bill yield (South Africa) }\end{array}$ & N/A \\
\hline SPREADN_TBILL & $\begin{array}{l}\text { Short-term spread between prime overdraft rate and 3- } \\
\text { month Treasury Bill yield (South Africa) }{ }^{27}\end{array}$ & N/A \\
\hline SPREADN_TERM & $\begin{array}{l}\text { Term spread between 10-year Government Bond yield } \\
\text { and 3-month Treasury Bill yield (South Africa) }\end{array}$ & N/A \\
\hline \multicolumn{3}{|c|}{ Variables used in forecasting tests } \\
\hline INFL & Month-on-month growth in CPI (South Africa) & $\begin{array}{l}\text { Seasonally adjusted, month-on- } \\
\text { month rate of change }\end{array}$ \\
\hline MANUFN_GR & $\begin{array}{l}\text { Month-on-month growth in Manufacturing Production } \\
\text { Index (South Africa) }\end{array}$ & Month-on-month rate of change \\
\hline TBILLN & 3-month Treasury Bill Yield (South Africa) & $\mathrm{N} / \mathrm{A}$ \\
\hline
\end{tabular}

Note: All data is extracted from the Global Financial Database (https://www.globalfinancialdata.com).

\footnotetext{
${ }^{26}$ Thompson, et al. (forthcoming) tested the inclusion of M1 growth vs. M3 growth through graphical comparison and correlation coefficients between the two FCIs and found that they were very similar, nearly identical in fact, so they chose the FCI including M3 since it is theoretically a more inclusive measure.

${ }^{27}$ This short spread captures the profitability of commercial banks.
} 
Figure 2. Estimated rolling-window purged FCI compared with key macroeconomic variables (12-month moving averages)

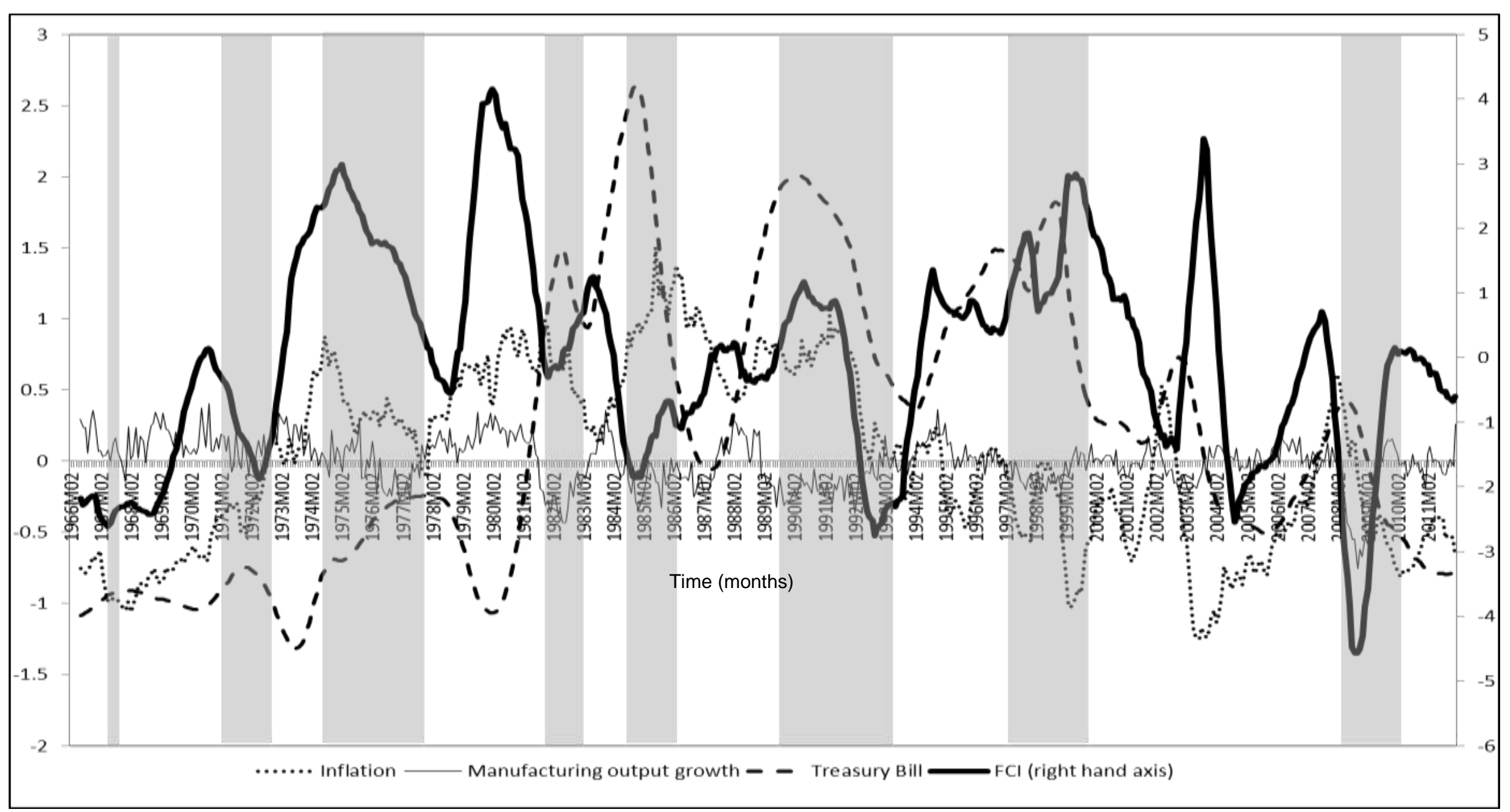

Notes: The grey vertical bars represent periods of recession in the South African economy. The series are represented as 12-month moving averages since the volatility of the high-frequency monthly data makes graphical interpretation difficult. Positive values of the FCI indicate "positive" financial conditions, and vice versa for "negative" financial conditions. 
Table 7. Out-of-sample forecasting for Xt: FCI (Sample: 1986:01 - 2012:01)28,29

\begin{tabular}{|c|c|c|c|c|c|c|c|c|c|}
\hline $\begin{array}{r}\text { Horizon (h) } \\
\text { months ahead: }\end{array}$ & $1 \mathrm{~m}$ & $3 \mathrm{~m}$ & $6 \mathrm{~m}$ & $9 m$ & $12 \mathrm{~m}$ & $15 \mathrm{~m}$ & $18 \mathrm{~m}$ & $21 \mathrm{~m}$ & $24 \mathrm{~m}$ \\
\hline \multicolumn{10}{|c|}{ Manufacturing production growth as dependent variable } \\
\hline$q_{1}$ & 9 & 10 & 7 & 4 & 2 & 2 & 2 & 2 & 2 \\
\hline$q_{2}$ & 12 & 10 & 9 & 12 & 12 & 12 & 12 & 12 & 12 \\
\hline Wald & $34.808(0.000)^{* * *}$ & $23.057(0.008)^{* * *}$ & $14.834(0.064)^{*}$ & $22.267(0.038)^{* *}$ & $20.599(0.058)^{*}$ & $25.111(0.018)^{* *}$ & $20.510(0.046)^{* *}$ & $27.421(0.014)^{* *}$ & $22.786(0.026)^{* *}$ \\
\hline Theil's U & 1.032 & 1.005 & 0.976 & 0.985 & 1.029 & 1.049 & 1.060 & 1.058 & 1.066 \\
\hline MSE-T & $-1.383(0.678)$ & $-0.105(0.218)$ & $0.392(0.092)^{*}$ & $0.246(0.140)$ & $-0.586(0.366)$ & $-1.066(0.574)$ & $-1.450(0.734)$ & $-1.452(0.754)$ & $-1.477(0.746)$ \\
\hline MSE-F & $-19.169(0.984)$ & $-2.973(0.508)$ & $15.121(0.020)^{* *}$ & $9.176(0.060)^{*}$ & $-16.859(0.726)$ & $-27.096(0.832)$ & $-32.363(0.858)$ & $-31.488(0.804)$ & $-34.591(0.872)$ \\
\hline ENC-T & $1.351(0.058)^{*}$ & $1.585(0.064)^{*}$ & $1.752(0.048)^{* *}$ & $2.068(0.032)^{* *}$ & $1.974(0.048)^{* *}$ & $2.155(0.028)^{* *}$ & $2.198(0.042)^{* *}$ & $2.109(0.034)^{* *}$ & $1.332(0.114)$ \\
\hline ENC-NEW & $9.376(0.002)^{* * *}$ & $23.158(0.002)^{* * *}$ & $36.250(0.004)^{* * *}$ & $40.079(0.006)^{* * *}$ & $28.372(0.030)^{* *}$ & $26.080(0.036)^{* *}$ & $24.168(0.056)^{*}$ & $23.177(0.048)^{* *}$ & $15.279(0.082)^{*}$ \\
\hline \multicolumn{10}{|c|}{ Inflation as dependent variable } \\
\hline$q_{1}$ & 12 & 12 & 12 & 12 & 12 & 12 & 12 & 12 & 12 \\
\hline$q_{2}$ & 1 & 1 & 1 & 1 & 1 & 2 & 2 & 1 & 1 \\
\hline Wald & $0.008(0.972)$ & $0.598(0.630)$ & $2.046(0.470)$ & $3.502(0.364)$ & $4.084(0.334)$ & $7.583(0.254)$ & $6.655(0.244)$ & $3.189(0.388)$ & $2.740(0.398)$ \\
\hline Theil's U & 1.004 & 1.008 & 1.003 & 0.994 & 0.986 & 0.982 & 0.980 & 0.990 & 0.992 \\
\hline MSE-T & $-1.312(0.668)$ & $-1.907(0.866)$ & $-0.319(0.280)$ & $0.538(0.084)^{*}$ & $0.967(0.040)^{* *}$ & $1.043(0.062)^{*}$ & $0.928(0.054)^{*}$ & $0.499(0.134)$ & $0.389(0.184)$ \\
\hline MSE-F & $-2.612(0.688)$ & $-5.042(0.684)$ & $-1.739(0.270)$ & $3.955(0.116)$ & $8.446(0.074)^{*}$ & $11.338(0.078)^{*}$ & $12.086(0.070)^{*}$ & $6.018(0.140)$ & $4.415(0.174)$ \\
\hline ENC-T & $-1.089(0.786)$ & $-1.672(0.914)$ & $-0.051(0.420)$ & $0.842(0.190)$ & $1.300(0.120)$ & $1.378(0.102)$ & $1.258(0.112)$ & $0.817(0.222)$ & $0.701(0.256)$ \\
\hline ENC-NEW & $-1.063(0.850)$ & $-2.187(0.852)$ & $-0.140(0.416)$ & $3.239(0.236)$ & $5.959(0.186)$ & $7.952(0.156)$ & $8.553(0.154)$ & $4.949(0.252)$ & $3.980(0.266)$ \\
\hline \multicolumn{10}{|c|}{ Treasury Bill as dependent variable } \\
\hline$q_{1}$ & 12 & 12 & 12 & 2 & 2 & 11 & 11 & 11 & 10 \\
\hline$q^{2}$ & 6 & 9 & 9 & 8 & 12 & 6 & 6 & 6 & 6 \\
\hline Wald & $13.285(0.046)^{* *}$ & $20.753(0.012)^{* *}$ & $19.123(0.026)^{* *}$ & $17.077(0.062)^{*}$ & $27.514(0.004)^{* * *}$ & $21.190(0.020)^{* *}$ & $22.263(0.018)^{* *}$ & $22.466(0.024)^{* *}$ & $20.861(0.032)^{* *}$ \\
\hline Theil's U & 1.032 & 1.044 & 1.044 & 1.046 & 1.075 & 1.030 & 1.019 & 1.016 & 1.030 \\
\hline MSE-T & $-1.969(0.836)$ & $-1.758(0.812)$ & $-1.254(0.588)$ & $-1.031(0.520)$ & $-1.440(0.738)$ & $-0.600(0.338)$ & $-0.404(0.274)$ & $-0.317(0.262)$ & $-0.577(0.346)$ \\
\hline MSE-F & $-18.951(0.972)$ & $-25.903(0.978)$ & $-25.312(0.916)$ & $-26.117(0.854)$ & $-40.755(0.906)$ & $-17.113(0.678)$ & $-11.162(0.526)$ & $-8.946(0.448)$ & $-16.657(0.650)$ \\
\hline ENC-T & $-0.410(0.542)$ & $-0.373(0.528)$ & $0.240(0.298)$ & $0.759(0.174)$ & $0.719(0.210)$ & $1.158(0.116)$ & $1.460(0.098)^{*}$ & $1.613(0.074)^{*}$ & $1.397(0.100)$ \\
\hline ENC-NEW & $-1.859(0.910)$ & $-2.599(0.892)$ & $2.348(0.214)$ & $9.480(0.086)^{*}$ & $9.796(0.106)$ & $18.307(0.054)^{*}$ & $22.475(0.046)^{* *}$ & $24.622(0.050)^{*}$ & $21.425(0.058)^{*}$ \\
\hline
\end{tabular}

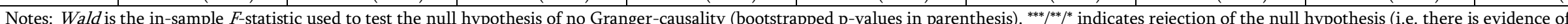
in-sample Granger causality) at the $1 / 5 / 10 \%$ level of significance. If Theil's $U<1$ then $R M S F E$ of the unrestricted model is $<R M S F E$ of the restricted model, indicating the relevance of the individual financial variables as "forecasters" (i.e. lower Theil's $U$ values are preferable). MSE-T and $M S E-F$ test the null hypothesis of equal forecasting ability between the restricted and unrestricted models (bootstrapped pvalues in parenthesis). ${ }^{* * * * * * *}$ indicates rejection of the null hypothesis (i.e. the financial variables of the unrestricted model have out-of-sample forecasting ability) at the $1 / 5 / 10 \%$ level of significance. $E N C$ - $T$ and $E N C-N E W$ test the null hypothesis that the restricted model forecast encompasses the unrestricted model forecast (bootstrapped p-values in parenthesis). ${ }^{* * * * * *}{ }^{*}$ indicates rejection of the null hypothesis (i.e. the financial variables of the unrestricted model are relevant in out-of-sample forecasting) at the $1 / 5 / 10 \%$ level of significance. A full set of test results for all sixteen explanatory variables is available upon request.

${ }^{28}$ Results similar to these for the out-of-sample periods of 1973:01-2012:01 and 2000:01-2012:01 are available upon request.

${ }^{29}$ Results similar to these for the 16 individual series that make up the FCI are available upon request.

20 
Table 8. Data-mining critical values: Manufacturing output growth (Sample: 1986:01 - 2012:01)

\begin{tabular}{|c|c|c|c|c|c|c|c|c|c|c|c|c|c|c|c|}
\hline $\begin{array}{l}\text { Horizon (h) } \\
\text { months ahead: }\end{array}$ & \multicolumn{3}{|c|}{$1 \mathrm{~m}$} & \multicolumn{3}{|c|}{$3 \mathrm{~m}$} & \multicolumn{3}{|c|}{$6 \mathrm{~m}$} & \multicolumn{3}{|c|}{$9 \mathrm{~m}$} & \multicolumn{3}{|c|}{$12 \mathrm{~m}$} \\
\hline Signif. level & $10 \%$ & $5 \%$ & $1 \%$ & $10 \%$ & $5 \%$ & $1 \%$ & $10 \%$ & $5 \%$ & $1 \%$ & $10 \%$ & $5 \%$ & $1 \%$ & $10 \%$ & $5 \%$ & $1 \%$ \\
\hline MSE-T & 1.462 & 1.721 & 2.216 & 1.706 & 2.002 & 2.426 & 1.810 & 2.146 & 2.593 & 1.862 & 2.172 & 2.566 & 2.003 & 2.308 & 2.633 \\
\hline MSE-F & 5.017 & 6.316 & 9.507 & 11.688 & 16.220 & 26.142 & 21.576 & 31.392 & 62.040 & 30.894 & 44.151 & 91.718 & 38.962 & 59.100 & 116.629 \\
\hline ENC-T & 2.424 & 2.749 & 3.257 & 2.631 & 2.947 & 3.692 & 2.733 & 3.082 & 3.701 & 2.802 & 3.047 & 3.701 & 2.830 & 3.110 & 3.679 \\
\hline ENC- NEW & 7.560 & 9.438 & 12.798 & 15.237 & 19.660 & 31.998 & 28.654 & 34.113 & 67.469 & 40.171 & 53.984 & 91.397 & 50.672 & 64.294 & 106.003 \\
\hline $\begin{array}{l}\text { Horizon (h) } \\
\text { months ahead: }\end{array}$ & \multicolumn{3}{|c|}{$15 \mathrm{~m}$} & \multicolumn{3}{|c|}{$18 \mathrm{~m}$} & \multicolumn{3}{|c|}{$21 \mathrm{~m}$} & \multicolumn{3}{|c|}{$24 \mathrm{~m}$} & & & \\
\hline Signif. Level & $10 \%$ & $5 \%$ & $1 \%$ & $10 \%$ & $5 \%$ & $1 \%$ & $10 \%$ & $5 \%$ & $1 \%$ & $10 \%$ & $5 \%$ & $1 \%$ & & & \\
\hline MSE-T & 1.985 & 2.291 & 2.860 & 2.113 & 2.380 & 2.882 & 2.223 & 2.557 & 3.167 & 2.285 & 2.629 & 3.457 & & & \\
\hline MSE-F & 50.496 & 69.384 & 136.545 & 62.009 & 81.822 & 169.537 & 69.937 & 97.042 & 197.734 & 73.639 & 107.495 & 186.938 & & & \\
\hline ENC-T & 2.958 & 3.274 & 3.787 & 2.958 & 3.354 & 3.975 & 3.133 & 3.590 & 3.979 & 3.145 & 3.553 & 4.436 & & & \\
\hline ENC- NEW & 58.429 & 77.733 & 123.427 & 69.120 & 91.071 & 161.215 & 77.761 & 102.705 & 193.248 & 85.866 & 114.643 & 204.596 & & & \\
\hline
\end{tabular}

Table 9. Data-mining critical values: Inflation (Sample: 1986:01 - 2012:01)

\begin{tabular}{|c|c|c|c|c|c|c|c|c|c|c|c|c|c|c|c|}
\hline \multirow{2}{*}{$\begin{array}{l}\text { Horizon (h) } \\
\text { months ahead: } \\
\text { Signif. level } \\
\end{array}$} & \multicolumn{3}{|c|}{$1 \mathrm{~m}$} & \multicolumn{3}{|c|}{$3 m$} & \multicolumn{3}{|c|}{$6 \mathrm{~m}$} & \multicolumn{3}{|c|}{$9 \mathrm{~m}$} & \multicolumn{3}{|c|}{$12 \mathrm{~m}$} \\
\hline & $10 \%$ & $5 \%$ & $1 \%$ & $10 \%$ & $5 \%$ & $1 \%$ & $10 \%$ & $5 \%$ & $1 \%$ & $10 \%$ & $5 \%$ & $1 \%$ & $10 \%$ & $5 \%$ & $1 \%$ \\
\hline MSE-T & 1.869 & 2.481 & 4.375 & 2.015 & 2.581 & 3.526 & 1.997 & 2.312 & 3.456 & 2.110 & 2.451 & 3.232 & 2.126 & 2.414 & 3.212 \\
\hline MSE-F & 7.988 & 13.168 & 32.691 & 19.116 & 32.928 & 62.406 & 32.219 & 48.348 & 91.542 & 45.311 & 69.742 & 112.691 & 54.117 & 73.578 & 120.357 \\
\hline ENC-T & 3.171 & 3.811 & 5.910 & 3.163 & 3.928 & 4.860 & 3.019 & 3.486 & 4.723 & 3.037 & 3.373 & 4.039 & 3.037 & 3.381 & 4.005 \\
\hline ENC- NEW & 12.225 & 15.967 & 28.720 & 22.811 & 34.051 & 58.586 & 37.278 & 52.352 & 92.852 & 57.352 & 72.151 & 114.307 & 65.315 & 82.882 & 133.810 \\
\hline $\begin{array}{l}\text { Horizon (h) } \\
\text { months ahead: }\end{array}$ & \multicolumn{3}{|c|}{$15 \mathrm{~m}$} & \multicolumn{3}{|c|}{$18 \mathrm{~m}$} & \multicolumn{3}{|c|}{$21 \mathrm{~m}$} & \multicolumn{3}{|c|}{$24 \mathrm{~m}$} & & & \\
\hline Signif. Level & $10 \%$ & $5 \%$ & $1 \%$ & $10 \%$ & $5 \%$ & $1 \%$ & $10 \%$ & $5 \%$ & $1 \%$ & $10 \%$ & $5 \%$ & $1 \%$ & & & \\
\hline MSE-T & 2.171 & 2.510 & 3.260 & 2.355 & 2.648 & 3.128 & 2.311 & 2.669 & 3.388 & 2.347 & 2.651 & 3.500 & & & \\
\hline MSE-F & 58.049 & 80.568 & 148.550 & 64.207 & 93.424 & 172.767 & 74.641 & 107.274 & 187.621 & 78.612 & 115.642 & 217.775 & & & \\
\hline ENC-T & 3.093 & 3.315 & 3.990 & 3.150 & 3.374 & 4.159 & 3.229 & 3.597 & 4.303 & 3.323 & 3.737 & 4.339 & & & \\
\hline ENC- NEW & 73.786 & 89.356 & 154.512 & 80.017 & 101.484 & 179.619 & 88.857 & 123.484 & 193.259 & 95.280 & 128.037 & 226.038 & & & \\
\hline
\end{tabular}


Table 10. Data-mining critical values: Treasury Bill (Sample: 1986:01 - 2012:01)

\begin{tabular}{|c|c|c|c|c|c|c|c|c|c|c|c|c|c|c|c|}
\hline $\begin{array}{l}\text { Horizon (h) } \\
\text { months ahead: }\end{array}$ & \multicolumn{3}{|c|}{$1 \mathrm{~m}$} & \multicolumn{3}{|c|}{$3 \mathrm{~m}$} & \multicolumn{3}{|c|}{$6 \mathrm{~m}$} & \multicolumn{3}{|c|}{$9 m$} & \multicolumn{3}{|c|}{$12 \mathrm{~m}$} \\
\hline Signif. level & $10 \%$ & $5 \%$ & $1 \%$ & $10 \%$ & $5 \%$ & $1 \%$ & $10 \%$ & $5 \%$ & $1 \%$ & $10 \%$ & $5 \%$ & $1 \%$ & $10 \%$ & $5 \%$ & $1 \%$ \\
\hline MSE-T & 1.520 & 1.724 & 2.163 & 1.742 & 1.981 & 2.406 & 1.738 & 2.020 & 2.845 & 1.854 & 2.130 & 2.836 & 1.899 & 2.184 & 2.801 \\
\hline MSE-F & 6.167 & 7.620 & 15.479 & 12.538 & 15.198 & 29.998 & 22.007 & 26.825 & 70.474 & 28.711 & 39.478 & 62.352 & 37.511 & 50.186 & 65.141 \\
\hline ENC-T & 2.765 & 3.161 & 3.977 & 2.919 & 3.238 & 3.852 & 2.796 & 3.165 & 3.746 & 2.845 & 3.209 & 3.727 & 2.887 & 3.209 & 3.804 \\
\hline ENC- NEW & 11.510 & 15.781 & 24.419 & 18.317 & 22.676 & 33.983 & 27.737 & 34.239 & 61.712 & 38.389 & 45.381 & 68.956 & 47.020 & 54.181 & 86.643 \\
\hline $\begin{array}{l}\text { Horizon (h) } \\
\text { months ahead: }\end{array}$ & \multicolumn{3}{|c|}{$15 \mathrm{~m}$} & \multicolumn{3}{|c|}{$18 \mathrm{~m}$} & \multicolumn{3}{|c|}{$21 \mathrm{~m}$} & \multicolumn{3}{|c|}{$24 \mathrm{~m}$} & & & \\
\hline Signif. level & $10 \%$ & $5 \%$ & $1 \%$ & $10 \%$ & $5 \%$ & $1 \%$ & $10 \%$ & $5 \%$ & $1 \%$ & $10 \%$ & $5 \%$ & $1 \%$ & & & \\
\hline MSE-T & 1.914 & 2.171 & 2.758 & 1.934 & 2.239 & 2.704 & 2.037 & 2.392 & 2.905 & 2.165 & 2.474 & 2.991 & & & \\
\hline MSE-F & 44.064 & 55.651 & 80.062 & 50.677 & 65.494 & 88.620 & 55.828 & 73.260 & 111.002 & 63.960 & 90.264 & 154.627 & & & \\
\hline ENC-T & 2.893 & 3.274 & 3.978 & 2.910 & 3.274 & 4.013 & 2.977 & 3.292 & 4.222 & 3.056 & 3.426 & 4.417 & & & \\
\hline ENC- NEW & 51.913 & 64.678 & 109.027 & 60.272 & 78.075 & 112.763 & 68.498 & 88.789 & 137.973 & 78.218 & 102.649 & 170.944 & & & \\
\hline
\end{tabular}

Notes for Table 8 to Table 10: MSE-T and MSE-F test the null hypothesis of equal forecasting ability between the restricted and unrestricted models (bootstrapped p-values in parenthesis). ${ }^{* * * * * *} *$ indicates rejection of the null hypothesis (i.e. the financial variables of the unrestricted model have out-of-sample forecasting ability) at the 1/5/10\% level of significance. ENC-T and ENC-NEW test the null hypothesis that the restricted model forecast encompasses the unrestricted model forecast (bootstrapped p-values in parenthesis). ${ }^{* * * * * / *}$ indicates rejection of the null hypothesis (i.e. the financial variables of the unrestricted model are relevant in out-of-sample forecasting) at the $1 / 5 / 10 \%$ level of significance. 